\title{
EDITORIAL
}

\section{Treating pulmonary hypertension in COPD: where do we start?}

\author{
M.M. Hoeper
}

E ndothelin receptor antagonists, phosphodiesterase (PDE)-5 inhibitors and prostanoids are effective treatments for pulmonary arterial hypertension (PAH), a severe but relatively rare form of pulmonary hypertension [1-3]. Other forms of pulmonary hypertension as seen, for instance, in chronic lung disease are much more common than $\mathrm{PAH}$ and although usually less severe, they are clinically meaningful as they are associated with aggravated symptoms and shorter survival $[4,5]$. Thus, it comes as no surprise that physicians are tempted to use so-called $\mathrm{PAH}$ drugs in other forms of pulmonary hypertension, even though there is limited evidence supporting this approach.

In this issue of the European Respiratory Journal (ERJ), STOLZ et al. [6], from the University Hospital Basel (Basel, Switzerland), report on the results of a small randomised placebo-controlled study they conducted to assess the safety and efficacy of the endothelin receptor antagonist bosentan in patients with chronic obstructive pulmonary disease (COPD). The study included 30 patients with advanced COPD at Global Initiative for Chronic Obstructive Lung Disease (GOLD) stages III and IV. It is noteworthy that the presence of pulmonary hypertension at rest was not an inclusion criterion as the authors reasoned that pulmonary hypertension during exercise was to be expected in the majority of their patients [7]. In fact, echocardiography at baseline showed no evidence for pulmonary hypertension at rest in 24 out of the 30 patients. The rationale of the study of STOLZ et al. [6] was that by lowering pulmonary artery pressure and improving right ventricular function, bosentan might improve exercise capacity in these patients. However, after 12 weeks, patients treated with bosentan did not show improvement in 6min walking distance as compared with the placebo group. The same was true for the maximum oxygen uptake. In fact, bosentan treatment was associated with detrimental effects since arterial oxygenation deteriorated significantly as did health-related quality of life. In line with these findings, a recent study using the PDE-5 inhibitor sildenafil in COPD patients also found no improvement in exercise capacity [8].

Despite its obvious limitations, which include a small sample size, low statistical power, the lack of invasive haemodynamic assessments and a short observation period, the study by

STATEMENT OF INTEREST: A statement of interest for M.M. Hoeper can be found at www.erj.ersjournals.com/misc/statements.shtml

CORRESPONDENCE: M.M. Hoeper, Dept of Respiratory Medicine, Hannover Medical School, CarlNeuberg-Str. 1, 30625 Hannover, Germany. Fax: 49 5115328536. E-mail: hoeper.marius@ mh-hannover.de
STOLZ et al. [6] has important clinical implications. It reminds us that not all forms of pulmonary hypertension will respond in a similar manner to certain drugs and that treatments that have beneficial effects in one form of pulmonary hypertension may have no or even adverse effects in another. This is not surprising as there are fundamental pathophysiological differences in $\mathrm{PAH}$ and COPD-related pulmonary hypertension. $\mathrm{PAH}$ is characterised by progressive pulmonary vascular remodelling, eventually resulting in right heart failure with elevated filling pressures and low cardiac output [9]. Pulmonary vascular remodelling is also seen in COPD-related pulmonary hypertension [10] but it usually progresses very slowly [7,11]. Low output right ventricular failure is exceedingly rare in COPD-related pulmonary hypertension and unlike $\mathrm{PAH}$ patients, these patients almost never die from right heart failure. What we tend to call "cor pulmonale" is in fact a hypertrophied and dilated right ventricle with elevated filling pressures, i.e. predominantly diastolic dysfunction. In contrast to the low cardiac output usually seen in patients with advanced PAH, the cardiac output remains normal in the vast majority of patients with COPDrelated pulmonary hypertension [12]. COPD exacerbations may be accompanied by clinical signs suggestive of right heart failure, such as fluid retention and oedema, but the pathomechanisms underlying this clinical picture are complex, and once again are dominated by right ventricular diastolic dysfunction rather than a low cardiac output. In PAH patients, bosentan acts predominantly by increasing cardiac output rather than by reducing pulmonary artery pressure [13]. During exercise, bosentan reduces isoflow pulmonary artery pressure, i.e. the pulmonary artery pressure at a given cardiac output [14]. In conditions where cardiac output is normal, which is the case in the majority of COPD patients, pulmonary vasodilators like bosentan or sildenafil simply may not work.

In addition, the study by STOLz et al. [6] reminds us that pulmonary vasodilators have the potential to worsen gas exchange in patients with COPD. This phenomenon was observed years ago with calcium channel blockers [15] as well as with other vasodilators [4], and it is not surprising that we see the same problem with newer drugs.

Given the profound impact that the development of pulmonary hypertension has on quality of life and survival in patients with chronic lung disease, it is obvious that we need to study whether and how we can treat this condition. But which approach should we take? Probably, we should first look at those patients who are most likely to respond. CHAOUAT et al. [16] identified a subpopulation of COPD patients with "out-of-proportion" pulmonary hypertension. These patients were characterised by 
severe pulmonary hypertension, arbitrarily defined by a mean pulmonary artery pressure $>40 \mathrm{mmHg}$ at rest. It is worth noting that these patients did not have end-stage COPD but rather moderate airflow obstruction (a mean forced expiratory volume in one second $50 \%$ of the predicted value) and showed some characteristic clinical features, such as a very low diffusion capacity for carbon monoxide, profound hypoxaemia and hyperventilation. The prognosis of these patients was particularly grim, with a 5 -yr survival rate of $\sim 10 \%$, compared with 5-yr survival rates of nearly $60 \%$ in patients with less severe pulmonary hypertension and almost $90 \%$ in patients without pulmonary hypertension. Given the impact on survival and the fact that the symptoms of these patients were probably driven by the pulmonary vascular component rather than by airflow obstruction, this could be the first subgroup of COPD patients to be studied further.

Short-term pilot trials should address safety (including tolerability and gas exchange) and preliminary efficacy (exercise capacity and haemodynamics). Some detrimental effects on gas exchange are to be expected with any pulmonary vasodilator if the effect on ventilation-perfusion matching is not counteracted by an increase in cardiac output, but this must not necessarily preclude beneficial clinical effects. In any case, pivotal studies with drugs that have yielded promising results during the pilot phase must address solid end-points, such as survival and health-related quality of life over a long period of time. In addition to that, if drugs prove efficacious in patients with moderate COPD but severe pulmonary hypertension, further trials must assess safety and efficacy in COPD patients with more advanced airflow obstruction but less severe pulmonary hypertension, as the clinical response to pulmonary vasodilators may vary substantially. Thus, the patients under study must be carefully characterised, which should include right heart catheterisation, at least at baseline. Echocardiography alone is not sufficiently reliable in these patients $[17,18]$ as the challenge is to find out with as much certainty as possible which patients will and will not derive benefit from these treatments.

The recommendations from the 4th World Symposium on Pulmonary Hypertension, which took place in Dana Point (CA, USA) in February 2008 are expected to be published by the end of 2008 or early 2009. These will provide similar suggestions for studying pulmonary hypertension in the setting of chronic lung disease. For the time being we should be reluctant to use so-called PAH drugs in patients with COPD-associated pulmonary hypertension. STOLz et al. [6] are to be commended not only for performing this important pilot study but also for their decision to publish its negative results.

\section{REFERENCES}

1 Dupuis J, Hoeper MM. Endothelin receptor antagonists in pulmonary arterial hypertension. Eur Respir J 2008; 31: 407-414.
2 Olschewski H, Gomberg-Maitland M. Prostacyclin therapies for the treatment of pulmonary arterial hypertension. Eur Respir J 2008; 31: 801-901.

3 Wilkins MR, Wharton J, Grimminger F, Ghofrani HA. Phosphodiesterase inhibitors for the treatment of pulmonary hypertension. Eur Respir J 2008; 32: 198-209.

4 Chaouat A, Naeije R, Weitzenblum E. Pulmonary hypertension in chronic obstructive pulmonary disease. Eur Respir J 2008; (In press).

5 Behr J, Ryu JH. Pulmonary hypertension in interstitial lung disease. Eur Respir J 2008; 31: 1357-1367.

6 Stolz D, Rasch H, Linka A, et al. A randomised, controlled trial of bosentan in severe COPD. Eur Respir J 2008; 32: 619-628.

7 Kessler R, Faller M, Weitzenblum E, et al. "Natural history" of pulmonary hypertension in a series of 131 patients with chronic obstructive lung disease. Am J Respir Crit Care Med 2001; 164: 219-224.

8 Rietema H, Holverda S, Bogaard HJ, et al. Sildenafil treatment in COPD does not affect stroke volume or exercise capacity. Eur Respir J 2008; 31: 759-764.

9 Farber HW, Loscalzo J. Pulmonary arterial hypertension. N Engl J Med 2004; 351: 1655-1665.

10 Santos S, Peinado VI, Ramirez J, et al. Characterization of pulmonary vascular remodelling in smokers and patients with mild COPD. Eur Respir J 2002; 19: 632-638.

11 Weitzenblum E, Sautegeau A, Ehrhart M, Mammosser M, Hirth C, Roegel E. Long-term course of pulmonary arterial pressure in chronic obstructive pulmonary disease. Am Rev Respir Dis 1984; 130: 993-998.

12 Scharf SM, Iqbal M, Keller C, Criner G, Lee S, Fessler HE. Hemodynamic characterization of patients with severe emphysema. Am J Respir Crit Care Med 2002; 166: 314-322.

13 Channick RN, Simonneau G, Sitbon O, et al. Effects of the dual endothelin-receptor antagonist bosentan in patients with pulmonary hypertension: a randomised placebocontrolled study. Lancet 2001; 358: 1119-1123.

14 Provencher S, Hervé P, Sitbon O, Humbert M, Simonneau G, Chemla D. Changes in exercise haemodynamics during treatment in pulmonary arterial hypertension. Eur Respir J 2008; [Epub ahead of print PMID: 18417516].

15 Simonneau G, Escourrou P, Duroux P, Lockhart A. Inhibition of hypoxic pulmonary vasoconstriction by nifedipine. N Engl J Med 1981; 304: 1582-1585.

16 Chaouat A, Bugnet AS, Kadaoui N, et al. Severe pulmonary hypertension and chronic obstructive pulmonary disease. Am J Respir Crit Care Med 2005; 172: 189-194.

17 Fisher MR, Criner GJ, Fishman AP, et al. Estimating pulmonary artery pressures by echocardiography in patients with emphysema. Eur Respir J 2007; 30: 914-921.

18 Arcasoy SM, Christie JD, Ferrari VA, et al. Echocardiographic assessment of pulmonary hypertension in patients with advanced lung disease. Am J Respir Crit Care Med 2003; 167: 735-740. 